\title{
"Internet+" Blended Learning Model and Practice Research from the Perspective of Smart Education
} -- Taking the Course "Thinking and Innovation" as an Example

\author{
Xiaohu Zhang a, ${ }^{\text {* }}$ and Ru Wang ${ }^{\text {b }}$ \\ General Education College of Xi'an Eurasia University, Xi'an, 710065, China \\ a, ${ }^{*}$ zhangxiaohu@eurasia.edu, bwangru@eurasia.edu
}

\begin{abstract}
In a comprehensive education environment, we must pay attention to cultivating students' thinking ability, and provide effective support for the cultivation of students' English literacy through the construction of a heuristic and participatory English teaching system, so that students' English practical application ability and comprehensive literacy can be cultivated. "Let's take root." Based on the introduction of the concept of blended learning mode, this article will combine with the book "The Development of "Thinking and Innovation" Teaching: Thinking and Innovation" to analyte the current innovation background and direction of "Thinking and Innovation" teaching. Explore the innovative mechanism of "Thinking and Innovation" teaching under the guidance of English core literacy nurturers, analyte the characteristics of the blended learning model and the necessity for the teaching reform of "Thinking and Innovation". On this basis, the relevant practical research of blended learning mode teaching is carried out.
\end{abstract}

Keywords: Smart Education; Blended Learning Model; Internet+; "Thinking and Innovation".

\section{Introduction}

With the improvement of China's international status and the increasing frequency of international exchanges, the development of the country and society has put forward higher requirements for college students' English ability. At present, Chinese "Thinking and Innovation" course is actively exploring the transition from the traditional "teacher-cantered" teaching model to the "studentcantered" teaching model. As the main course for cultivating students' listening and speaking ability, " The "Thinking and Innovation" course is no exception, but overall speaking, the listening and speaking courses are not effective in improving students' listening and speaking ability due to the influence of large-class teaching, single teaching mode, insufficient teaching facilities and technical means, etc., Even leading to the decline of students' enthusiasm for listening and speaking courses. At the same time, compared with reading and writing courses, many teachers are not so calm when facing listening and speaking courses [1]. However, with the rapid development of today's information technology and mobile technology, the coverage of wan, 3G, and 4G networks is expanding, and mobile electronic terminal devices such as smart phones, PDAs, and tablet computers are becoming more and more popular. Mobile technology assists English teaching and Learning has become a hot topic discussed in the English education circle. Therefore, how to use mobile technology to construct a teaching model of "Thinking and Innovation" that conforms to the characteristics of English subjects and the law of language learning has also become a major research topic.

\section{Introduction to Blended Learning}

Blended learning refers to a strategy that uses different learning theories, different technologies and methods, and different application methods to implement teaching. It organically integrates the two typical teaching forms of face-to-face classroom learning and digital learning. It has become the main trend of current ICT teaching application, and its purpose is to integrate the advantages of classroom teaching and network teaching, and comprehensively adopt the collective teaching form based on teacher lectures, the group teaching form based on the concept of "cooperation" and the selfdirected learning. Teaching form [2]. Blended learning is a mixture of performance support, cognitive 
learning theory, and constructivist learning theory. It is a mixture of learning resources, a mixture of learning environments, a mixture of learning methods, and a mixture of learning styles. "Blended learning is an improvement of the learning philosophy. This improvement has changed the cognitive style of students and the teaching mode, teaching strategy and role of teachers. Its core idea is to adopt different problems and requirements. The way to solve the problem, specific to teaching, is to use different media and information transmission methods to solve the problem, and the purpose of this solution is to pay the least price and obtain the greatest benefit."

\subsection{Requirements for Changing the Concept of the Subject of English Teaching}

Under the traditional teaching model, teachers are the leaders between teachers and students, and students will inevitably lose the ability to learn actively. In the classroom, teachers explain English grammar knowledge, word interpretations, and difficult sentence patterns to students, but students can only listen to the lectures in their seats, which cannot activate the students' enthusiasm for learning, and ultimately leads to low overall teaching efficiency.

\subsection{Requirements for Enriching English Teaching Resources}

In traditional English teaching classrooms, English teachers usually use English textbooks to teach in the classroom. In this way, the updating of teaching resources is relatively slow, and it is difficult to adapt to the rapid social development speed. In the long run, the teaching content under this method is often inconsistent with the actual situation. There is a deviation in social applications. On the other hand, students only need to passively learn the knowledge taught in the classroom, but because they lose their initiative in the learning process, it will inevitably cause the symptoms of a decrease in students' interest in learning, which will reduce the teacher's teaching experience and cause teaching between teachers and students. The efficiency is reduced [3]. The blended learning model can not only use classic English teaching materials, but also make full use of the abundant English learning resources on the Internet to provide students with teaching resources that are closer to the language environment of the native English country.

\subsection{Requirements for Objective and Fair Assessment of Students' English Proficiency from Multiple Perspectives}

In the traditional English teaching process, when assessing students' English proficiency, they often use the face-to-face assessment method, which causes teachers to evaluate students too onesidedly. Because they pay less attention to the comprehensive application ability of students, they cannot effectively grasp the level of students. This method is also difficult to give teachers real-time feedback information to help them prepare appropriate teaching content.

\section{3. "Thinking and Innovation" Blended Learning Model}

The focus of language learning is the training of basic skills such as listening, speaking, reading, writing and translation, and at the same time improving students' intercultural communication skills. With the support of network technology and information technology, students can strengthen basic language skills through the network platform, carry out student-student interaction and teacherstudent interaction, and finally show what they have learned through the classroom (or network). Some scholars believe that blended learning is composed of four key links: curriculum introduction, activity organization, learning support, and teaching evaluation [4]. Integrating the domestic and foreign blended learning model and the integration model of information technology and foreign language courses, this article proposes the following "independent learning-network interactionclassroom face-to-face teaching" "Thinking and Innovation" blended learning model (Figure 1): 


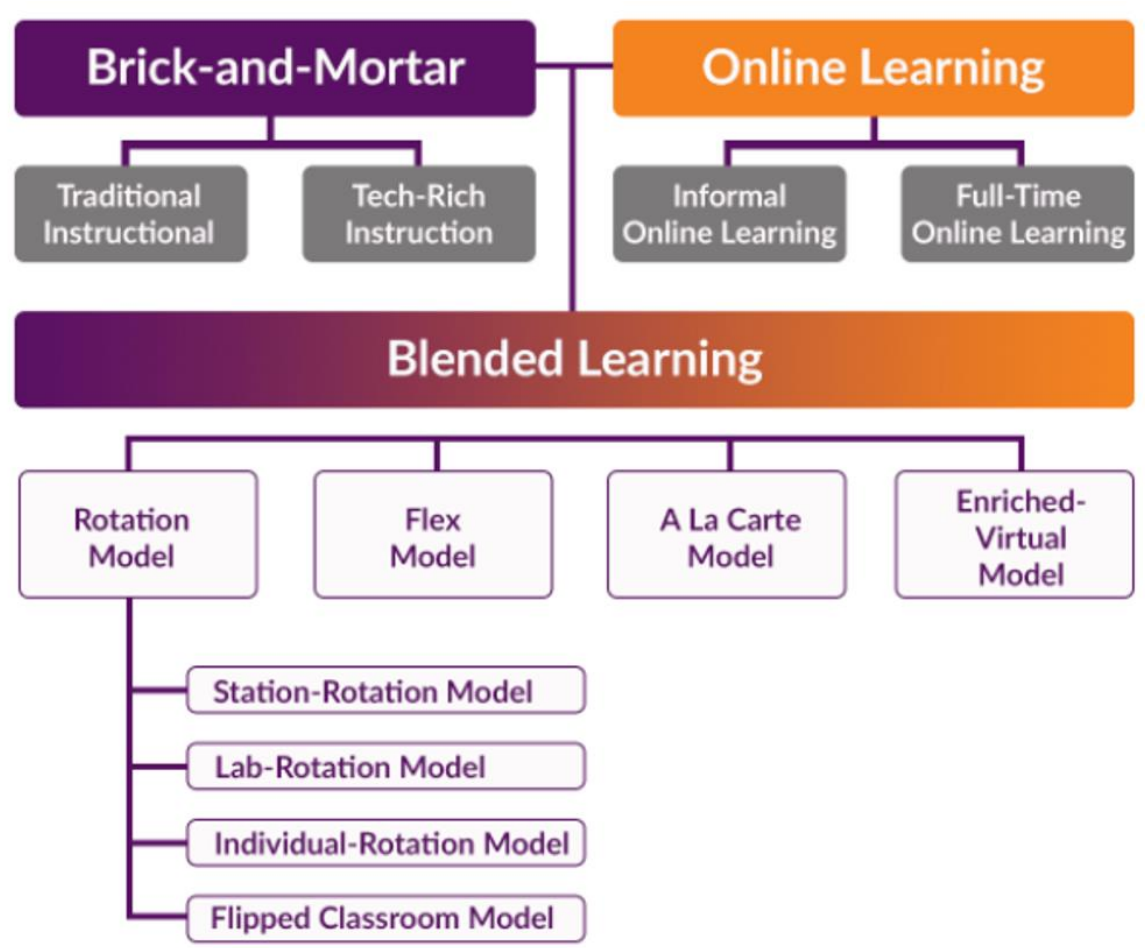

Figure 1. "Thinking and Innovation" blended learning model

This model divides the learning of "Thinking and Innovation" into three stages. The learning environment, learning content, learning method and evaluation method of each stage are different:

The first stage: independent learning. Learners use the "Thinking and Innovation" campus network platform (computer network 1) to carry out independent learning and complete "learning objective 1" ("visual listening, listening 1" + "reading and writing translation 1"), and the learning method is "individual autonomy", and then Students accept the corresponding "evaluation 1", if they fail the assessment, they continue to study at this stage; if they pass the assessment, they enter the second stage of study.

The second stage: network interaction. Learners communicate through the World Wide Web ("Computer Network 2") and corresponding network platforms (QQ, MSN, Faction, Weibo, etc.), and complete "Learning Objective 2" ("Visual Listening, Listening, Listening, 2" + reading and writing $2+1$ "). The learning method is "group collaboration", accept "evaluation 2" (including mutual evaluation of the learning content of the first stage between groups), if the evaluation fails, continue learning, and the evaluation passes, then it will enter the third stage.

The third stage; face-to-face instruction in class. Through the first and second stages of learning, learners successfully complete the "learning objective 1 " and "learning objective 2 " and enter the "teaching objective" (equivalent to "learning objective 3") learning, the learning content is "visual listening and speaking 3 " "And "Reading and Writing Translation $2+1$ ", the learning method is "group collaboration" and "teacher-student discussion". After the study is over, the third stage of evaluation ("evaluation 3") will be carried out [5]. If the evaluation is not passed, continue to consolidate the study, and evaluate Pass, accept the overall evaluation of this unit ("evaluation 4"), if pass "evaluation $4 "$, continue to the next unit of learning, otherwise return to the first stage to re-learn.

The above three stages constitute the key to the blended learning model, but front-end analysis (learner analysis, learning content and learning environment analysis) is not reflected as a regular part of teaching design, and the purpose is to highlight the main part of the blended learning model. However, front-end analysis is a prerequisite for the implementation of teaching activities, an organic part of successful teaching, and its importance is beyond doubt. 


\section{Course Practice Analysis}

\subsection{Research Content}

Through a one-year teaching practice and comparative study of parallel classes and experimental classes, we investigate students' satisfaction with the new hybrid "Thinking and Innovation" teaching method, the degree of improvement in students' listening and speaking skills, and the feasibility of the new teaching model.

\subsection{Subject}

The research group selected Class 1 and Class 4 of Business English of the Department of Business English as the subjects. There are 64 students in the two classes, including 35 in the control group and 29 in the experimental group. Pre-test the students' English listening and speaking ability when they enter the school. The results show that the English listening and oral expression levels of the two groups of students are basically the same [6]. Therefore, it is determined that there is no significant difference in the English listening and speaking proficiency of the two groups of students in the pretest.

\subsection{Test Tools}

Two forms of SPASS analysis software and questionnaires are used as test tools. Through analysis and questionnaire surveys, we can understand the effect of the web-based English listening mixed teaching model on the improvement of students' listening level and the satisfaction of this teaching method.

\subsection{Test Process}

The test process lasts for one year. The traditional teaching method of "Thinking and Innovation" is adopted for the students in parallel classes, and the students have 2 listening lessons every week. Teachers explain listening skills, play recordings, explain difficult words and sentences, students listen repeatedly, answer questions, etc., and there is basically no homework or listening and speaking tasks after class. The content of the "Thinking and Innovation" Learning System is adopted for the students in the experimental class, and the students are arranged to take classes in the language training room. The original two sessions of listening and speaking classes per week will be changed to one session per week, with face-to-face instruction once every other week. Students choose the level that suits them to study according to their actual English situation, and make a study plan, including the time and content of online learning after class [7]. They can study in the multimedia language training room, and they can also log in to the system through any computer terminal or even use a mobile phone to conduct independent and personalized learning.

\subsection{Experimental Results}

First, a post-test was conducted on the listening and speaking level of the two groups of students. 62 students participated in the post-test [8]. The A-level listening and speaking tests of the National Practical English Proficiency Test were selected. The two groups of students' listening comprehension expression and oral English pre- and post-test results are shown in Table 1 and Table 2 .

Table 1. Pre-test results statistics $(\mathrm{N}=64)$

\begin{tabular}{|c|c|c|c|}
\hline Pilot projects & Test object & Average value & Standard deviation \\
\hline \multirow{2}{*}{ Listening comprehension } & Parallel class & 20.31 & 2.178 \\
\cline { 2 - 4 } & Test class & 19.86 & 2.814 \\
\hline \multirow{2}{*}{ Oral expression } & Parallel class & 13.98 & 2.179 \\
\cline { 2 - 4 } & Test class & 15.05 & 2.286 \\
\hline
\end{tabular}


Table 2. Post-test results statistics $(\mathrm{N}=62)$

\begin{tabular}{|c|c|c|c|}
\hline Pilot projects & Test object & Average value & Standard deviation \\
\hline \multirow{2}{*}{ Listening comprehension } & Parallel class & 17.87 & 2.836 \\
\cline { 2 - 4 } & Test class & 21.90 & 2.067 \\
\hline \multirow{2}{*}{ Oral expression } & Parallel class & 13.05 & 2.098 \\
\cline { 2 - 4 } & Test class & 15.87 & 1.242 \\
\hline
\end{tabular}

It can be seen from Table 1 that the pre-test scores of the students are basically the same at the time of enrolment, and the gap is not large. The data in Table 2 shows that after one academic year of mixed "Thinking and Innovation" teaching practice, the two groups of students have undergone great changes in their listening comprehension and oral expression scores. The average difference between the two groups of listening and speaking scores was 4.03 and 2.82, respectively. The standard deviation of the experimental class was much larger than the standard deviation of the parallel class. Practice has proved that the use of modern educational technology and the use of a network-based hybrid English listening and speaking autonomous teaching model can help improve students' listening and speaking skills [9]. We also conducted a questionnaire survey on the satisfaction of the two teaching modes. The survey content includes teaching methods, learning content, training methods, learning effects, etc.

Table 3. Questionnaire statistics of students' satisfaction with the two teaching modes

\begin{tabular}{|c|c|c|c|c|c|c|}
\hline Project & Group & Very dissatisfied & Dissatisfied & General & Satisfaction & Very satisfied \\
\hline \multirow{2}{*}{ The way to teach } & Test class & $6.3 \%$ & $11.2 \%$ & $23.4 \%$ & $45.7 \%$ & $13.4 \%$ \\
\cline { 2 - 6 } & Parallel class & $11.4 \%$ & $15.8 \%$ & $19.1 \%$ & $39.2 \%$ & $14.5 \%$ \\
\hline \multirow{2}{*}{ Learning Content } & Test class & $2.6 \%$ & $5.3 \%$ & $26.4 \%$ & $30.1 \%$ & $35.6 \%$ \\
\cline { 2 - 6 } & Parallel class & $15.7 \%$ & $12.4 \%$ & $34.5 \%$ & $27.6 \%$ & $9.8 \%$ \\
\hline \multirow{2}{*}{ Training form } & Test class & $4.8 \%$ & $5.3 \%$ & $27.3 \%$ & $39.4 \%$ & $23.6 \%$ \\
\cline { 2 - 6 } & Parallel class & $17.3 \%$ & $18.4 \%$ & $32.7 \%$ & $18.7 \%$ & $13.3 \%$ \\
\hline \multirow{2}{*}{ learning result } & Test class & $2.4 \%$ & $3.3 \%$ & $20.2 \%$ & $41.7 \%$ & $37.4 \%$ \\
\cline { 2 - 6 } & Parallel class & $15.6 \%$ & $24.5 \%$ & $31.7 \%$ & $16.4 \%$ & $11.8 \%$ \\
\hline
\end{tabular}

From the questionnaire data statistics in Table 3, it can be seen that the satisfaction rates of the experimental class students for the teaching method, learning content, training form and learning effect of the hybrid "Thinking and Innovation" teaching model are 59.1\%, 65.6\%, and 63\%, respectively, And $79.1 \%$, far greater than the satisfaction rate of parallel class students, parallel class students are dissatisfied with the traditional "Thinking and Innovation" training form and effect close to $40 \%$. The results show that the two groups of students have great differences in teaching styles, learning content, training styles, and learning effects. The reformed mixed teaching model is more popular with students, and students' satisfaction is higher.

\section{Conclusion}

The network-based hybrid English "Thinking and Innovation" teaching model not only has the advantages of face-to-face communication in traditional classroom teaching, but also has the advantages of rich network resources, diverse media forms, and the realization of personalized learning of "time, everywhere, and everyone". Paying attention to the guidance, enlightenment, and monitoring role of teachers, and emphasizing the initiative and consciousness of students in learning, will help students improve their independent learning ability and cultivate life-long learning habits.

\section{Acknowledgments}

Funded by: "Internet+" Blended Learning Model and Practice Research from the Perspective of Smart Education, a school-level educational reform project of 2021 in Xi'an Eurasia University 
Volume 3 (2021)

(SGH20Z022). Shaanxi Provincial Education Science "Thirteenth Five-Year Plan" 2020 Project "Research on Classroom Teaching Reform in Shaanxi Universities in the New Era" (SGH20Z022).

\section{References}

[1] Xiao-Dong, L., \& Hong-Hui, C. Research on VR-supported flipped classroom based on blended learning-a case study in "learning English through news.". International Journal of Information and Education Technology, 10(2) (2020) 104-109.

[2] Fu, H., \& Wang, J. Cultivation of Critical Thinking Skills in College English Writing under Blended Learning Model. Creative Education, 12(7) (2021) 1485-1493.

[3] Yao, C. A case study of Chinese adult learners' English acquisition in a blended learning environment. Australian Journal of Adult Learning, 59(1) (2019) 115-135.

[4] Syakur, A., Fanani, Z., \& Ahmadi, R. The Effectiveness of Reading English Learning Process Based on Blended Learning through "Absyak" Website Media in Higher Education. Budapest International Research and Critics in Linguistics and Education (BirLE) Journal, 3(2) (2020) 763-772.

[5] Wang, N., Chen, J., Tai, M., \& Zhang, J. Blended learning for Chinese university EFL learners: learning environment and learner perceptions. Computer Assisted Language Learning, 34(3) (2021) 297-323.

[6] Alrouji, O. O. The Effectiveness of Blended Learning in Enhancing Saudi Students' Competence in Paragraph Writing. English Language Teaching, 13(9) (2020) 72-82.

[7] Liu, X., Zhang, L., Zhang, S., \& Tian, Y. The Further Study of the Blended Learning Model of the Videoaural-oral Course-the Combination of Web-based Learning, Flipped Classroom and Face-to-Face Instruction. Education Journal, 9(3) (2020) 64-72.

[8] Quvanch, Z., \& Na, K. S. A Review on Impact of Blended Learning on the English Writing Skills. Innovative Teaching and Learning Journal (ITLJ), 4(1) (2020) 41-50.

[9] Al Masri, A. The effectiveness of using blended learning for teaching English language vocabulary for 1 st grade students at Al Tafila Directorate of Education. International Journal of Education Research and Reviews, 8(8) (2020) 001-006. 